\title{
The Effects of a Primary Care Transformation Initiative on Primary Care Physician Burnout and Workplace Experience
}

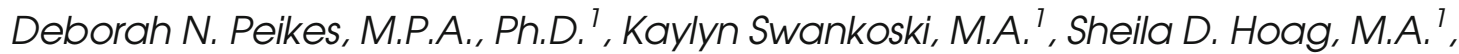 \\ Nancy Duda, Ph.D. ', Jared Coopersmith, Ph.D. ', Erin Fries Taylor, M.P.P., Ph.D. ',

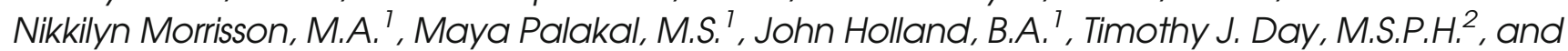 \\ Laura L. Sessums, J.D., M.D. ${ }^{2}$
}

'Mathematica Policy Research, Princeton, NJ, USA; ${ }^{2}$ Centers for Medicare \& Medicaid Services, Baltimore, MD, USA.

\begin{abstract}
BACKGROUND: Physician burnout is associated with deleterious effects for physicians and their patients and might be exacerbated by practice transformation.

OBJECTIVE: Assess the effect of the Comprehensive Primary Care (CPC) initiative on primary care physician experience.
\end{abstract}

DESIGN: Prospective cohort study conducted with about 500 CPC and 900 matched comparison practices. Mail surveys of primary care physicians, selected using crosssectional stratified random selection 11 months into CPC, and a longitudinal design with sample replacement 44 months into CPC.

PARTICIPANTS: Primary care physicians in study practices.

INTERVENTION: A multipayer primary care transformation initiative (October 2012-December 2016) that required care delivery changes and provided enhanced payment, data feedback, and learning support.

MAIN MEASURES: Burnout, control over work, job satisfaction, likelihood of leaving current practice within 2 years.

KEY RESULTS: More than 1000 physicians responded (over 630 of these in CPC practices) in each round (response rates $70-81 \%$, depending on round and research group). Physician experience outcomes were similar for physicians in CPC and comparison practices. About one third of physician respondents in CPC and comparison practices reported high levels of burnout in each round (32 and $29 \%$ in $2013[P=0.59]$, and 34 and $36 \%$ in $2016[P=$ 0.63]). Physicians in CPC and comparison practices reported some to moderate control over work, with an average score from 0.50 to 0.55 out of 1 in 2013 and 2016 (CPC-comparison differences of - 0.04 in 2013 [95\% CI $0.08-0.00, P=0.07$ ], and -0.03 in 2016 [95\% CI $-0.03-$ $0.02, P=0.19])$. In 2016, roughly three quarters of CPC and comparison physicians were satisfied with their current job (77 and $74 \%, P=0.77$ ) and about $15 \%$ planned to leave their practice within 2 years (14 and $15 \%, P=0.17$ ).

CONCLUSIONS: Despite requiring substantial practice transformation, CPC did not affect physician experience.

Electronic supplementary material The online version of this article (https://doi.org/10.1007/s11606-018-4545-0) contains supplementary material, which is available to authorized users.

Received December 27, 2017

Revised April 13, 2018

Accepted June 6, 2018

Published online July 17, 2018
Research should track effects of other transformation initiatives on physicians and test new ways to address burnout. TRIAL REGISTRATION: ClinicalTrials.gov number, NCT02320591

KEY WORDS: burnout; control over work; job satisfaction; patientcentered medical home; primary care physician.

J Gen Intern Med 34(1):49-57

DOI: $10.1007 / \mathrm{s} 11606-018-4545-0$

(C) Society of General Internal Medicine 2018

\section{INTRODUCTION}

As payers increasingly test practice transformation initiatives to improve primary care, more evidence is needed on how transformation affects physician experience. Providing primary care practices with more resources to support care delivery might improve physician experience. ${ }^{1}$ At the same time, such efforts require intensive work, including changing practice workflows and staffing substantially, shifting from a physician-centric to a team-based culture, and creating new clinical and administrative tasks. Such changes might add to physicians' burden, worsen their experience, and increase job dissatisfaction, at least in the short run.

Whether and in what contexts participation in transformation activities alters physicians' experiences are important questions. Burnout, defined as workplace stress that leads to emotional exhaustion, depersonalization, and a diminished sense of personal accomplishment, has been linked to negative effects for physicians and, in some studies, their patients. For the physician, these include lower work satisfaction, increased likelihood of decreasing clinical work hours or leaving medicine, disrupted personal relationships, substance abuse, depression, and even suicidal thoughts; for their patients, these include lower patient satisfaction, higher rates of medical error, and increased costs. ${ }^{2-13}$ Among primary care physicians, the proportion reporting burnout is high $-25 \%$ in two studies of national samples, ${ }^{14}, 15$ and $45 \%$ in a study of physicians practicing in Veterans Affairs primary care clinics. ${ }^{16}$

Evidence of the effects of practice transformation models on physicians' experiences is mixed. ${ }^{14,17-21}$ Two studies found unfavorable effects from transitioning to patient-centered 
medical homes (PCMHs). The National Demonstration Project (NDP) found that "the magnitude of stress and burden from the unrelenting, continual change required to implement components of the NDP was immense." ${ }^{\prime 17}$ The Centers for Medicare \& Medicaid Services (CMS) Federally Qualified Health Center Advanced Primary Care Practice Demonstration worsened burnout, control over work, and job satisfaction. ${ }^{21}$ In contrast, a PCMH pilot improved burnout, though it was tested in only one clinic. ${ }^{18,19}$ Finally, two studies suggest no effect on burnout, in Veterans Affairs clinics ${ }^{20}$ and in a cross-sectional study of primary care practices with and without PCMH recognition, though that study found worse burnout among practices participating in other types of practice transformation, namely accountable care organizations and those with meaningful use certification. ${ }^{14}$

This paper examines whether participation in the Comprehensive Primary Care (CPC) initiative had an effect on physician burnout, control over work, and job satisfaction. We studied this question by examining differences between physicians in CPC and comparison practices in 2013 and 2016, the first and last years of the initiative.

\section{THE COMPREHENSIVE PRIMARY CARE INITIATIVE}

CPC was a primary care payment and care delivery transformation model tested from October 2012 through December 2016 in nearly 500 diverse primary care practices in seven regions across the USA. CMS partnered with 39 public and private payers to provide practices with financial support; learning opportunities; and patient- and practice-level data feedback on cost, service use, and quality of care. CPC required participating practices to implement five primary care functions - access and continuity, planned care for chronic conditions and preventive care, risk-stratified care management, patient and caregiver engagement, and coordination of care with patients' other care providers - supported by enhanced payment, continuous improvement driven by data, and optimal use of health information technology. Although CMS allowed CPC practices latitude in how they changed care delivery and implemented the five functions, practices were required to meet a series of annual milestones to guide care delivery improvements. ${ }^{22}$

Financial support to practices came from care management fees from CMS and most of the 39 other payers, on top of traditional reimbursements. Beginning in year 2, support included the opportunity to share in any savings from CMS and two thirds of other payers. Care management fees were paid per attributed patient per month (and were not visit based). Care management fees were substantial; calculated as the median per clinician in the practice, annual payments were more than $\$ 50,000$ and, depending on the year, accounted for 10 to $20 \%$ of practice revenue.

CPC did not explicitly aim to reduce physician burnout or improve satisfaction. However, CPC might have improved physician experience, given its emphasis on using teamwork and allowing physicians (and other practice staff) to spend more of their time on tasks commensurate with their licensure. In addition, practices could use the care management fees for activities related to improving care and transforming their organization, such as supporting non-billable practitioner time, augmenting care teams (e.g., hiring care mangers), and investing in technology or data analysts. Together, these changes potentially allowed physicians to better care for their patients. On the other hand, CPC participation required considerable work for practices, including changes in workflows and integration of new staff (e.g., care managers), regular reporting to CMS and other payers on their progress, and participation in CPC learning activities (both in person and virtual). Physician perspectives on the benefits of data feedback and learning activities varied. Because CPC could have both favorable and unfavorable effects on physician burnout and satisfaction, the expected effects overall were indeterminate.

\section{METHODS}

\section{Survey Administration}

We mailed two rounds of surveys to a stratified random sample of primary care physicians in CPC and comparison practices. The first round was fielded September 2013 to March 2014, 11 to 17 months after CPC began; the second round was fielded June to November 2016, 44 to 50 months after CPC began. Estimated completion time was 15 to 25 minutes. Fielding included up to five questionnaire mailings, three thank-you/ reminder postcard mailings, up to two telephone reminder calls for all sampled physicians, and email reminders for some physicians. We enclosed a $\$ 100$ check in the initial questionnaire mailing as an incentive to complete the voluntary survey.

\section{Sampling}

The sampling frame included primary care physicians working at $\mathrm{CPC}$ and comparison practice sites. We propensity score-matched CPC practices to comparison practices based on market-, practice-, and patient-level characteristics before CPC. ${ }^{23}$ The size of the matched sets varied from $1 \mathrm{CPC}$ practice matched with 5 comparison practices to $3 \mathrm{CPC}$ practices matched with 1 comparison practice; the average ratio was 1.8 comparison practices to each CPC practice. We identified medical doctors and doctors of osteopathy most likely to provide primary care, using SK\&A's national database of more than 2.1 million health care providers. We identified eligible physicians as those working at the practices with a national provider identifier and an SK\&A specialty code of general practice, family practice, internal medicine, geriatrics, or internal medicine/pediatrics.

In 2013, we randomly selected from each CPC practice one physician (for solo practices) or two physicians (for other practices) and one to three physicians from each matched set of comparison practices. In 2016, we retained the physicians 
from the 2013 sample, replacing physicians who departed the practices with previously unselected physicians and/or those entering the practices since 2013. Thus, survey estimates in each round reflect responses from all physicians in the practices, regardless of tenure at the practice. In total, we sent surveys to 867 of the $1831 \mathrm{CPC}$ physicians and 714 of the 3113 comparison physicians in 2013 and to 912 of the 1677 CPC physicians and 788 of the 2981 comparison physicians in 2016 (Table 1). Because we sampled from each practice for CPC practices and from each matched set for the comparison practices, we sent surveys to physicians in $100 \%$ of CPC practices and 51\% of comparison practices in 2013 and 59\% in 2016.

\section{Nonresponse Adjustments}

To reduce potential bias from survey nonresponse, we applied a response propensity adjustment to each respondent's sample weight. These adjustments were calculated using logistic regressions with response as the outcome and a set of characteristics of the physician's practice, its county, and its attributed Medicare fee-for-service beneficiaries that predicted response. Adjustments were calculated separately for CPC and comparison physicians in each round.

\section{Measures}

To measure burnout, we used two single-question measures related to level and frequency of burnout (both of which have been validated against the Maslach Burnout Inventory, or MBI) ${ }^{24-27}$ and three scales that reflect dimensions of burnout (based on a shortened version of the MBI that uses 9 of the 22 questions): emotional exhaustion, depersonalization, and reduced personal accomplishment (Table 2). ${ }^{28}$

To measure control over work, we used a scale that summarizes physicians' responses about how much control they have over seven areas of work: (1) their work hours, (2) details of the office or practice schedule, (3) their volume of paperwork, (4) work interruptions, (5) workplace issues, (6) their work pace, and (7) the allotment of additional time for difficult-tohelp patients. ${ }^{29}$
To measure job satisfaction, we asked, using a 5-point Likert scale, (1) how much physicians agreed or disagreed that they are satisfied with their current job and (2) the likelihood that they will leave their current practice within 2 years and their primary reason for leaving. ${ }^{25}$

\section{Analysis}

Because we were not able to survey physicians before CPC, differences in either round may reflect preexisting differences between $\mathrm{CPC}$ and comparison respondents. In case $\mathrm{CPC}$ affected experiences before the first round, we did not calculate difference-in-differences estimates.

For each question, we calculated the distribution of responses among CPC and comparison practices. Because of low question nonresponse - between 0 and $2 \%$ per question - we calculated results among nonmissing responses. CPC responses were weighted for their probability of selection into the sample and were adjusted for survey nonresponse. Comparison responses were weighted to reflect comparison group matching and were adjusted for survey nonresponse. We also created scales to parsimoniously measure each of the three dimensions of burnout and control over work. Scales average nonmissing responses for component items (each rescaled so responses range from 0 to 1 and are oriented so larger values signify more favorable responses).

For each question and scale, separately for each round, we statistically compared the responses of physicians in CPC practices to those in comparison practices, using chi-square tests for distributions and two-sided $t$ tests for means and binaries. Given similar characteristics of physicians in CPC and comparison practices after weighting, we did not regression-adjust the results. We also examined whether physicians who reported high burnout had less control over work, lower job satisfaction, and different demographics than those who did not report high burnout, combining CPC and comparison physicians. We clustered standard errors by practice for respondents in CPC practices and by matched set for respondents in comparison practices. Analyses were conducted using SAS 9.4, using survey commands for tests to account for the survey sampling design.

Table 1 Population and Sample Sizes, and Weighted Survey Response Rates, by Round

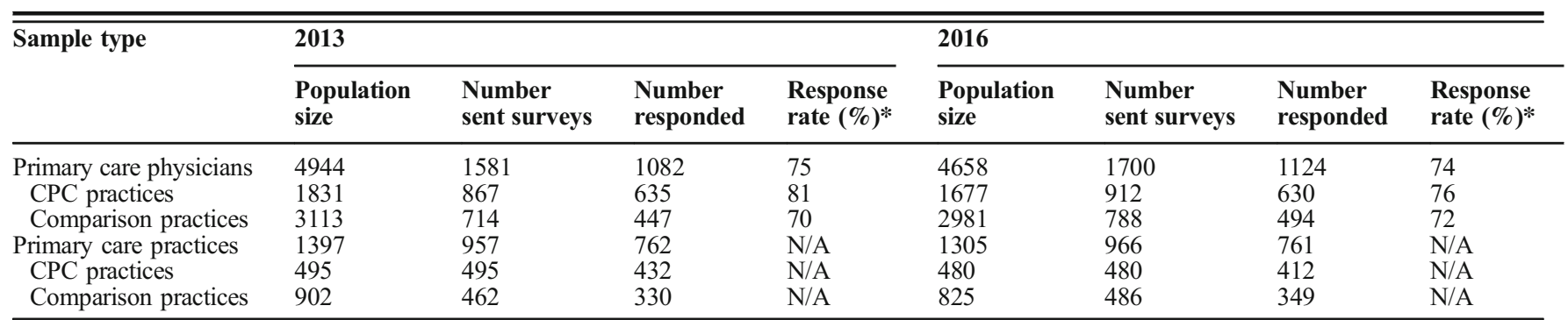

*We used Response Rate 3 calculations from the American Association for Public Opinion Research Standard Definitions, which uses the observed eligibility rate among those with known eligibility status to estimate the number eligible among those with unknown eligibility status. ${ }^{33}$ Response rates were weighted using the sample design weights

N/A = not applicable 
Table 2 Survey Questions and Topics Measuring Physician Experience

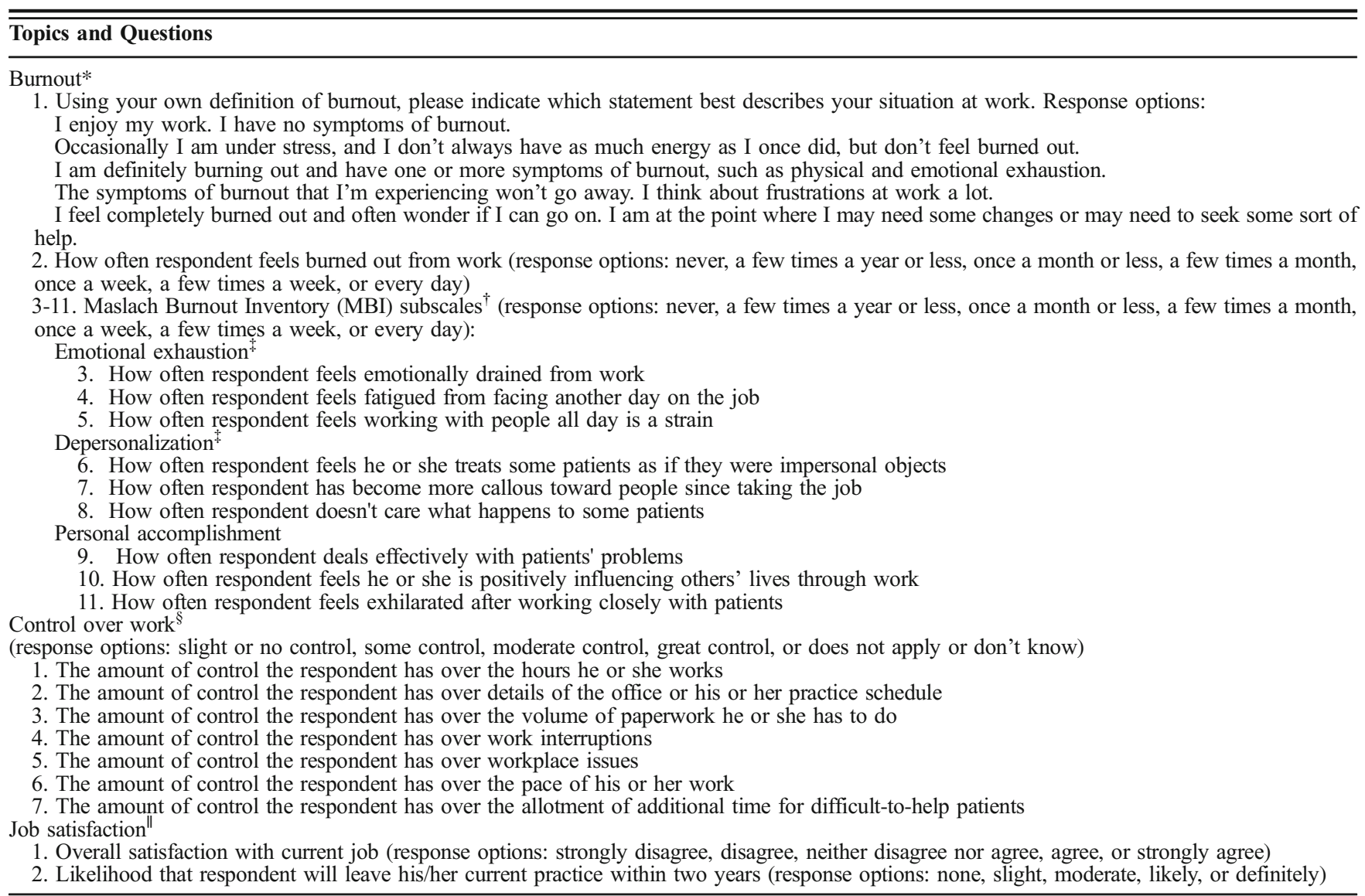

* The first question was used in the Federally Qualified Health Center Advanced Primary Practice Provider and Staff Survey developed by the RAND Corporation ${ }^{25,27}$ The second question is 1 of the 22 questions in the $M B I^{24}$ validated as a single-question measure of burnout ${ }^{26}$

tThe MBI contains 22 questions organized into the three subscales. ${ }^{24}$ We use an abbreviated version of the subscales containing the 9 questions used in an evaluation of the Patient-Aligned Care Team (PACT) Personnel Survey ${ }^{28}$

$\neq$ Responses to the questions in this subscale were reverse-coded when we constructed the composite measure, so the most favorable response received the largest value

${ }^{\xi}$ The seven questions in the control-over-work scale were used in a modified version of the Agency for Healthcare Research and Quality (AHRQ) Minimizing Errors and Maximizing Outcomes (MEMO) survey ${ }^{29}$

"The two questions were used in the Federally Qualified Health Center Advanced Primary Practice Provider and Staff Survey developed by the RAND Corporation $^{25}$

Using two-tailed tests at the $5 \%$ significance level, the analysis had $80 \%$ power to detect differences between responses of physicians in CPC and comparison practices of 8 to 12 percentage points for the categorical variables and 0.07 to 0.12 points out of 1 for the scales.

To limit the chance of false positives from multiple testing, we focus results on CPC-comparison differences in each survey round and do not examine changes over time within each research group. Instead of reporting on all outcomes, we report tests in each round of the two single-question measures of burnout, three MBI scales, one control-of-work scale, and two satisfaction questions, for a total of 16 tests (our primary tests). We would expect one test to be statistically significant by chance. We also consider both statistical significance and the size of the difference. (The tables also report secondary tests of the questions in each of the scales.)

\section{RESULTS}

Respondents. More than 1000 physicians from about 760 practices responded in each round. More than 630 of these responding physicians were from CPC practices. Weighted response rates ranged from 70 to $81 \%$, depending on the round and research group (Table 1). These respondents practiced in $86 \%$ of CPC practices, and, 37 to $42 \%$ of comparison practices, depending on the round (the lower proportion of comparison practices represented reflects the sample selection within matched sets).

Responding physicians in CPC and comparison practices reported similar gender, age, race, ethnicity, and tenure at the practice, after weighting for selection probability, matching, and nonresponse (Table 3). In 2016, about two thirds of the respondents were male, more than half were age 50 or older, $86 \%$ were 
Table 3 Characteristics of Physician Respondents

\begin{tabular}{|c|c|c|c|c|c|c|}
\hline & \multicolumn{6}{|c|}{ Primary care physician } \\
\hline & \multicolumn{3}{|l|}{2013} & \multicolumn{3}{|l|}{2016} \\
\hline & CPC & Comp & $\mathbf{P}$ & CPC & Comp & $\mathbf{P}$ \\
\hline $\begin{array}{l}\text { Number of } \\
\text { respondents* }\end{array}$ & 628 & 441 & & 628 & 491 & \\
\hline \multicolumn{7}{|c|}{ Physician characteristics reported in the survey } \\
\hline Male $(\%)$ & 60 & 68 & 0.04 & 62 & 68 & 0.13 \\
\hline $\begin{array}{l}\text { Respondent's } \\
\text { current age }(\%)\end{array}$ & & & 0.38 & & & 0.52 \\
\hline $\begin{array}{l}\text { Fewer than } 20 \\
\text { years }\end{array}$ & 0 & 0 & & 0 & 0 & \\
\hline $20-29$ & 0 & 0 & & 0 & 0 & \\
\hline $30-39$ & 18 & 13 & & 15 & 19 & \\
\hline $40-49$ & 30 & 29 & & 28 & 27 & \\
\hline $50-59$ & 32 & 37 & & 29 & 24 & \\
\hline $\begin{array}{l}60 \text { years or } \\
\text { older }\end{array}$ & 21 & 21 & & 28 & 29 & \\
\hline $\begin{array}{l}\text { Hispanic or } \\
\text { Latino }(\%)\end{array}$ & 2 & 2 & 0.57 & 2 & 2 & 0.79 \\
\hline \multicolumn{7}{|c|}{ Respondent's race $(\%)$} \\
\hline $\begin{array}{l}\text { White/ } \\
\text { Caucasian }\end{array}$ & 90 & 88 & 0.47 & 86 & 86 & 0.77 \\
\hline $\begin{array}{l}\text { Black or } \\
\text { African } \\
\text { American }\end{array}$ & 1 & 1 & 0.18 & 2 & 2 & 0.90 \\
\hline Asian & 8 & 10 & 0.42 & 10 & 10 & 0.75 \\
\hline $\begin{array}{l}\text { Native } \\
\text { Hawaiian or } \\
\text { other Pacific } \\
\text { Islander }\end{array}$ & 0 & 0 & 0.09 & 1 & 0 & 0.53 \\
\hline $\begin{array}{l}\text { American } \\
\text { Indian or } \\
\text { Alaska } \\
\text { Native }\end{array}$ & 1 & 1 & 0.19 & 2 & 0 & 0.0 \\
\hline Other & 1 & 2 & 0.13 & 2 & 4 & 0.11 \\
\hline \multicolumn{7}{|c|}{ How long respondent has worked at the practice $(\%)$} \\
\hline$<6$ months & 0 & 1 & 0.26 & 0 & 0 & 0.47 \\
\hline 6 months -1 year & 1 & 0 & & 2 & 5 & \\
\hline $1-2$ years & 7 & 3 & & 5 & 6 & \\
\hline $2-5$ years & 14 & 14 & & 13 & 14 & \\
\hline $5-10$ years & 19 & 19 & & 19 & 18 & \\
\hline$>10$ years & 59 & 62 & & 59 & 56 & \\
\hline
\end{tabular}

Note: We adjusted all results for the probability of selection into the sample, comparison group matching, and survey nonresponse

*The number of respondents is the maximum number of respondents in the denominator for any of these questions. The number of respondents for which we had information varied due to item nonresponse. For CPC practices, the minimum number of responses was 624 in 2013 and 623 in 2016. For comparison practices, the minimum number of respondents was 438 in 2013 and 486 in 2016

white, and more than half had worked at the practice for more than 10 years.

Burnout. CPC and comparison physicians responded similarly to the various burnout measures. About one third of physicians in both CPC and comparison practices reported high levels of burnout in each round, based on the severity of symptoms reported (32 and $29 \%$ in $2013[P=0.59]$, and 34 and $36 \%$ in 2016 $[P=0.63])$. When asked how often they felt burned out from their work in the past year, $44 \%$ of CPC physicians and $47 \%$ of comparison physicians reported feeling burned out a few times a month or more in 2016; another $15 \%$ of CPC physicians and $10 \%$ of comparison physicians reported burnout more than a few times a year $(P=0.27$; Table 4$)$. Using the three dimensions of burnout from the $M B I$, mean scores were comparable for CPC and comparison practices in 2013 and in 2016. The only statistically significant difference was on the depersonalization scale in 2013, and it was small (0.03 out of $1.0,95 \%$ CI $0.01-0.06, P=0.02)$. Physicians in both $\mathrm{CPC}$ and comparison practices reported more symptoms of emotional exhaustion than depersonalization or lack of personal accomplishment, although we did not statistically test differences between the three scales.

Control Over Work. Physicians in both CPC and comparison practices had an average score from 0.50 to 0.55 on a 1-point scale indicating some to moderate control over work in 2013 and 2016 (differences in mean scores were -0.04 out of 1 in 2013 (95\% CI $-0.08-0.00, P=0.07)$ and -0.03 in $2016(95 \%$ $\mathrm{CI}-0.08-0.02, P=0.19$; Table 5). Physicians in both groups reported having the most control over the hours they work and the details of the office or the practice schedule, and the least amount of control over work interruptions such as telephone calls and unscheduled patients, and the volume of paperwork (Table 5).

Job Satisfaction. In 2013 and 2016, there were no statistically significant differences between $\mathrm{CPC}$ and comparison physicians' reported job satisfaction. In 2016, 48\% of physicians in CPC practices and $45 \%$ of physicians in comparison practices agreed, and $29 \%$ of physicians in CPC and comparison practices strongly agreed, that they were satisfied with their current job (Table 6). For both CPC and comparison physicians, only about $15 \%$ disagreed or strongly disagreed with the statement, and $10 \%$ neither agreed nor disagreed $(P=0.77)$. Responses for both research groups were also similar in 2013.

A comparable $14 \%$ of CPC and $15 \%$ of comparison physicians reported in 2016 that they were likely or definitely leaving their current practice in the next 2 years $(P=0.17$; Table 6); more than half of these physicians were 60 or older $(52 \%$ of CPC physicians and $62 \%$ of comparison physicians, data not shown). Reasons for leaving included retirement, high workload, career advancement, moving, inadequate compensation or benefits, poor management, and "too many regulations."

Burnout and Control Over Work and Job Satisfaction, for CPC and Comparison Physicians Combined. Physicians who reported high burnout reported lower control over each aspect of work and less job satisfaction than physicians without high burnout (Appendix Table 1). For example, in 2016, the average control over work score was 0.43 on a 1-point scale for physicians who reported high levels of burnout, compared to 0.59 for those who reported less burnout $(95 \% \mathrm{CI}-0.20,-0.12$ point difference, $P<0.001)$. The average job satisfaction rating was 3.1 
Table 4 Burnout Among Primary Care Physicians in CPC and Comparison Practices, 2013 and 2016

\begin{tabular}{|c|c|c|c|c|c|c|c|c|}
\hline & \multicolumn{4}{|l|}{2013} & \multicolumn{4}{|l|}{2016} \\
\hline & CPC & Comp & Diff $(95 \%$ CI $)$ & $\mathbf{P}$ & CPC & Comp & Diff $(95 \%$ CI $)$ & $\mathbf{P}$ \\
\hline Number of respondents* & 625 & 443 & & & 626 & 491 & & \\
\hline \multicolumn{9}{|c|}{ Using respondent's own definition of burnout, statement that best describes respondent's situation at work ${ }^{\dagger}(\%)$} \\
\hline Low burnout & 68 & 71 & N/A & 0.59 & 66 & 64 & $\mathrm{~N} / \mathrm{A}$ & 0.63 \\
\hline High burnout & 32 & 29 & & & 34 & 36 & & \\
\hline \multicolumn{9}{|c|}{ How often respondent felt burned out from work in the past year (\%) } \\
\hline Never to a few times a year & 41 & 42 & N/A & 0.41 & 42 & 43 & $\mathrm{~N} / \mathrm{A}$ & 0.27 \\
\hline Once a month or less & 13 & 16 & & & 15 & 10 & & \\
\hline A few times a month to every day & 47 & 42 & & & 44 & 47 & & \\
\hline \multicolumn{9}{|c|}{ Emotional exhaustion subscale (0 [more exhausted] to 1 [less exhausted]) } \\
\hline Mean score & 0.57 & 0.55 & $\begin{array}{l}0.02 \\
(-0.02,0.06)\end{array}$ & 0.40 & 0.57 & 0.57 & $\begin{array}{l}0.01 \\
(-0.03,0.05)\end{array}$ & 0.67 \\
\hline \multicolumn{9}{|c|}{ Depersonalization subscale ( 0 [more depersonalization] to 1 [less depersonalization]) } \\
\hline Mean score & 0.87 & 0.84 & $\begin{array}{l}0.03 \\
(0.01,0.06)\end{array}$ & 0.02 & 0.87 & 0.86 & $\begin{array}{l}0.02 \\
(-0.01,0.05)\end{array}$ & 0.19 \\
\hline \multicolumn{9}{|c|}{ Personal accomplishment subscale (0 [less accomplishment] to 1 [more accomplishment]) } \\
\hline Mean score & 0.88 & 0.86 & $(-0.00,0.04)$ & 0.051 & 0.87 & 0.85 & $\begin{array}{l}0.02 \\
(-0.00,0.04)\end{array}$ & 0.07 \\
\hline \multicolumn{9}{|c|}{ Secondary tests of questions in MBI Subscales } \\
\hline \multicolumn{9}{|c|}{ How often respondent feels emotionally drained from work $(\%)$} \\
\hline Never to a few times a year & 21 & 20 & N/A & 0.91 & 22 & 22 & $\mathrm{~N} / \mathrm{A}$ & 0.45 \\
\hline Once a month or less & 11 & 10 & & & 11 & 8 & & \\
\hline A few times a month to every day & 69 & 70 & & & 67 & 70 & & \\
\hline \multicolumn{9}{|c|}{ How often respondent feels fatigued from facing another day on the job $(\%)$} \\
\hline Never to a few times a year & 38 & 34 & $\mathrm{~N} / \mathrm{A}$ & 0.30 & 38 & 35 & $\mathrm{~N} / \mathrm{A}$ & 0.68 \\
\hline Once a month or less & 16 & 13 & & & 14 & 14 & & \\
\hline A few times a month to every day & 47 & 53 & & & 48 & 51 & & \\
\hline \multicolumn{9}{|c|}{ How often respondent feels working with people all day is a strain (\%) } \\
\hline Never to a few times a year & 57 & 52 & N/A & 0.10 & 54 & 57 & $\mathrm{~N} / \mathrm{A}$ & 0.73 \\
\hline Once a month or less & 10 & 16 & & & 12 & 11 & & \\
\hline A few times a month to every day & 33 & 33 & & & 34 & 32 & & \\
\hline \multicolumn{9}{|c|}{ How often respondent feels he or she treats some patients as if they were impersonal objects $(\%)$} \\
\hline Never to a few times a year & $80^{\circ}$ & 73 & $\mathrm{~N} / \mathrm{A}$ & 0.04 & 83 & 78 & $\mathrm{~N} / \mathrm{A}$ & 0.23 \\
\hline Once a month or less & 8 & 8 & & & 6 & 10 & & \\
\hline A few times a month to every day & 12 & 19 & & & 10 & 12 & & \\
\hline \multicolumn{9}{|c|}{ How often respondent feels she or he has become more callous toward people since taking the job $(\%)$} \\
\hline Never to a few times a year & 73 & $66^{1}$ & $\mathrm{~N} / \mathrm{A}$ & 0.07 & 71 & 68 & $\mathrm{~N} / \mathrm{A}$ & 0.64 \\
\hline Once a month or less & 7 & 12 & & & 10 & 11 & & \\
\hline A few times a month to every day & 20 & 22 & & & 19 & 21 & & \\
\hline \multicolumn{9}{|c|}{ How often respondent doesn't care what happens to some patients $(\%)$} \\
\hline Never to a few times a year & 92 & 91 & $\mathrm{~N} / \mathrm{A}$ & 0.45 & 92 & 90 & $\mathrm{~N} / \mathrm{A}$ & 0.01 \\
\hline Once a month or less & 5 & 4 & & & 6 & 5 & & \\
\hline A few times a month to every day & 3 & 5 & & & 2 & 5 & & \\
\hline \multicolumn{9}{|c|}{$\begin{array}{l}\text { How often respondent deals effectively with patients' } \\
\text { problems }(\%)\end{array}$} \\
\hline Never to a few times a year & 0 & 0 & $\mathrm{~N} / \mathrm{A}$ & $\mathrm{N} / \mathrm{D}$ & 0 & 0 & $\mathrm{~N} / \mathrm{A}$ & $\mathrm{N} / \mathrm{D}$ \\
\hline Once a month or less & 0 & 0 & & & 0 & 0 & & \\
\hline A few times a month to every day & 99 & 100 & & & 100 & 100 & & \\
\hline \multicolumn{9}{|c|}{ How often respondent feels she or he positively influences others' lives through work (\%) } \\
\hline Never to a few times a year & 0 & 0 & $\mathrm{~N} / \mathrm{A}$ & 0.31 & 1 & 2 & $\mathrm{~N} / \mathrm{A}$ & 0.86 \\
\hline Once a month or less & 1 & 2 & & & 1 & 1 & & \\
\hline A few times a month to every day & 99 & 98 & & & 98 & 98 & & \\
\hline \multicolumn{9}{|c|}{ How often respondent feels exhilarated after working closely with patients (\%) } \\
\hline Never to a few times a year & 4 & 8 & $\mathrm{~N} / \mathrm{A}$ & 0.10 & 5 & 10 & $\mathrm{~N} / \mathrm{A}$ & 0.09 \\
\hline Once a month or less & 5 & 7 & & & 6 & 5 & & \\
\hline A few times a month to every day & 91 & 85 & & & 89 & 85 & & \\
\hline
\end{tabular}

Note: We adjusted all results for the probability of selection into the sample, comparison group matching, and survey nonresponse

*The number of respondents is the maximum number of respondents in the denominator for any of these questions. The number of respondents for which we had information varied due to item nonresponse. For CPC practices, the minimum number of responses was 622 in 2013 and 617 in 2016. For comparison practices, the minimum number of respondents was 440 in 2013 and 488 in 2016

tWe defined no or low burnout as responses of: I enjoy my work. I have no symptoms of burnout; or Occasionally I am under stress, and I don't always have as much energy as I once did, but I don't feel burned out. We defined high burnout as responses of: I am definitely burning out and have one or more symptoms of burnout, such as physical and emotional exhaustion; or The symptoms of burnout that I'm experiencing won't go away. I think about frustrations at work a lot; or I feel completely burned out and often wonder if I can go on. I am at the point where I may need some changes or may need to seek some sort of help

N/A Not applicable because the comparison is a comparison of distributions

N/D We were unable to perform chi-squared tests because of the small cell counts

out of 5.0 for physicians who reported high levels of burnout compared to 4.2 for those with less burnout $(95 \%$ CI -1.36 , -
0.99 point difference, $P<0.001)$. In $2016,27 \%$ of physicians who reported high levels of burnout reported that they were likely 
Table 5 Average Control over Work Among Primary Care Physicians in CPC and Comparison Practices, 2013 and 2016

\begin{tabular}{|c|c|c|c|c|c|c|c|c|}
\hline & \multicolumn{4}{|l|}{2013} & \multicolumn{4}{|l|}{2016} \\
\hline & CPC & Comp & Diff $(95 \% \mathrm{CI})$ & $\mathbf{P}$ & CPC & Comp & Diff $(95 \% \mathrm{CI})$ & $\mathbf{P}$ \\
\hline Number of respondents* & 626 & 442 & & & 624 & 490 & & \\
\hline Control-over-work scale ( 0 [less control] to 1 [more control] $)$ & 0.50 & 0.54 & $\begin{array}{l}-0.04 \\
(-0.08,0.00)\end{array}$ & 0.07 & 0.52 & 0.55 & $\begin{array}{l}-0.03 \\
(-0.08,0.02)\end{array}$ & 0.19 \\
\hline \multicolumn{9}{|l|}{ Secondary tests of questions in scale } \\
\hline The hours they work & 3.03 & 3.15 & -0.11 & 0.21 & 3.10 & 3.18 & $\begin{array}{l}-0.23 \\
(-0.30,0.06)\end{array}$ & 0.19 \\
\hline Details of their office or practice schedule & 2.99 & 3.21 & $\begin{array}{l}-0.22 \\
(-0.40,-0.04)\end{array}$ & 0.02 & 3.09 & 3.24 & $\begin{array}{l}-0.15 \\
(-0.35,0.04)\end{array}$ & 0.11 \\
\hline $\begin{array}{l}\text { The volume of "paperwork" they have to do (on paper or } \\
\text { electronic) }\end{array}$ & 1.52 & 1.61 & $\begin{array}{l}-0.09 \\
(-0.22,0.05)\end{array}$ & 0.21 & 1.47 & 1.57 & $\begin{array}{l}-0.10 \\
(-0.24,0.04)\end{array}$ & 0.18 \\
\hline $\begin{array}{l}\text { Work interruptions (e.g., telephone calls, unscheduled } \\
\text { patients) }\end{array}$ & 2.18 & 2.24 & $\begin{array}{l}-0.06 \\
(-0.19,0.07)\end{array}$ & 0.36 & 2.12 & 2.15 & $\begin{array}{l}-0.02 \\
(-0.18,0.13)\end{array}$ & 0.78 \\
\hline Workplace issues (e.g., office space, facilities, supplies) & 2.45 & 2.63 & $\begin{array}{l}-0.18 \\
(-0.35,-0.00)\end{array}$ & 0.05 & 2.50 & 2.63 & $\begin{array}{l}-0.14 \\
(-0.32,0.05)\end{array}$ & 0.15 \\
\hline The pace of your work & 2.70 & 2.85 & $\begin{array}{l}-0.14 \\
(-0.31,0.02)\end{array}$ & 0.10 & 2.82 & 2.95 & $\begin{array}{l}-0.13 \\
(-0.32,0.07)\end{array}$ & 0.20 \\
\hline $\begin{array}{l}\text { The allotment of additional time for difficult-to-help } \\
\text { patients }\end{array}$ & 2.67 & 2.65 & $\begin{array}{l}0.02 \\
(-0.15,0.19)\end{array}$ & 0.85 & 2.83 & 2.83 & $\begin{array}{l}-0.01 \\
(-0.19,0.17)\end{array}$ & 0.94 \\
\hline
\end{tabular}

Note: We adjusted all results for the probability of selection into the sample, comparison group matching, and survey nonresponse

*The number of respondents is the maximum number of respondents in the denominator for any of these questions. The number of respondents for which we had information varied due to item nonresponse. For CPC practices, the minimum number of responses was 610 in 2013 and 609 in 2016. For comparison practices, the minimum number of respondents was 436 in 2013 and 483 in 2016

or definitely leaving their current practice within the next 2 years, compared to $9 \%$ of physicians with less burnout $(P<0.001)$.

\section{DISCUSSION}

In the first and last years of CPC, physicians in CPC and comparison practices reported similar burnout, control over work (such as paperwork and hours worked), job satisfaction, and plans to leave their practice, indicating that CPC did not alter physician experience. These results are encouraging given concerns that change fatigue from participation in this complex primary care delivery transformation would exacerbate burnout and lessen satisfaction among physicians.

However, the results from CPC and comparison practices combined raise two troubling issues. First, consistent with levels seen in other studies, ${ }^{14-16}$ primary care physicians in this study suffered from substantial burnout, with one third reporting high levels of burnout. Further, physicians on average reported only some to moderate control over many aspects of their work, with fairly low control on average over the volume of paperwork they have to do and workplace issues and interruptions. Physicians in both CPC and comparison practices who reported high burnout reported less control over work and less job satisfaction than physicians without high burnout, suggesting these aspects of physician experience are related. These results underscore risks for the affected physicians, their patients, and the future workforce of primary care physicians.

This study has several limitations. First, we used matching, rather than random assignment, to select comparison practices. Although comparison practices were similar to CPC practices on observable characteristics, differences in unobservable characteristics could have influenced physicians' experiences. Second,

Table 6 Job Satisfaction Among Primary Care Physicians in CPC and Comparison Practices, 2013 and 2016

\begin{tabular}{|c|c|c|c|c|c|c|}
\hline & \multicolumn{3}{|l|}{2013} & \multicolumn{3}{|l|}{2016} \\
\hline & CPC & Comp & $\mathbf{P}$ & CPC & Comp & $\mathbf{P}$ \\
\hline \multicolumn{7}{|c|}{ Respondent's agreement with the statement: Overall, I am satisfied with my current job (\%) } \\
\hline Strongly disagree & 5 & 4 & 0.75 & 5 & 7 & 0.77 \\
\hline Slightly disagree & 10 & 12 & & 10 & 11 & \\
\hline Neither disagree or agree & 10 & 12 & & 8 & 9 & \\
\hline Agree & 49 & 46 & & 48 & 45 & \\
\hline Strongly agree & 27 & 27 & & 29 & 29 & \\
\hline $\mathrm{N}$ & 620 & 434 & & 617 & 486 & \\
\hline \multicolumn{7}{|c|}{ Likelihood respondent will leave the current practice within two years $(\%)$} \\
\hline None & 48 & 46 & 0.37 & 52 & 44 & 0.17 \\
\hline Slight & 31 & 26 & & 24 & 26 & \\
\hline Moderate & 12 & 14 & & 11 & 15 & \\
\hline Likely & 6 & 10 & & 7 & 10 & \\
\hline Definitely & 3 & 4 & & 7 & 5 & \\
\hline $\mathrm{N}$ & 625 & 441 & & 614 & 489 & \\
\hline
\end{tabular}

Note: We adjusted all results for the probability of selection into the sample, comparison group matching, and survey nonresponse 
regions, payers, and practices volunteered to participate, so results are generalizable only to these practices and their physicians. Finally, we did not measure physicians' experiences before $\mathrm{CPC}$ and thus cannot rule out prior differences between physicians in $\mathrm{CPC}$ and comparison practices.

Although the evidence shows CPC did not adversely affect physicians' experiences, these results highlight opportunities for transformation initiatives and practices themselves (or their owners) to reduce burnout, improve delegation, and streamline administrative work. Studies have pointed to organizational change$\mathrm{s}$ - such as fostering communication between members of the health care team, cultivating a sense of teamwork, improving work flows, conducting targeted quality improvement projects, and increasing control over work - as promising strategies to reduce burnout and improve physician experience. ${ }^{1,5,30-32}$

\section{CONCLUSION}

Despite requiring practices to undertake substantial transformation and regularly report their progress, the CPC initiative did not affect primary care physicians' burnout, control over work, job satisfaction, or plans to leave their practice. Although this is good news, burnout remains a significant problem for primary care physicians. This poses substantial risks for the affected physicians, their patients, and the primary care workforce. Research should continue to track the effects of other transformation initiatives on physicians and test new ways to address burnout.

Contributors: John Kennedy and Leah Hackleman-Good for editing; Dr. Robert J. Reid for helping design the 2013 survey instrument.

Corresponding Author: Deborah N. Peikes, M.P.A., Ph.D.; Mathematica Policy Research, Princeton, NJ, USA (e-mail: dpeikes@mathematicampr.com).

Funding This study received financial support from the Department of Health and Human Services, Centers for Medicare and Medicaid Services (HHSM-500-2010-00026I/HHSM-500-T0006; HHSM-5002014-00034I/HHSM-500-TOO10).

\section{Compliance with Ethical Standards:}

Conflict of Interest: The authors declare that they do not have a conflict of interest.

Disclaimer: The contents of this publication are solely the responsibility of the authors and do not necessarily represent the official views of the US Department of Health and Human Services or any of its agencies.

\section{REFERENCES}

1. Wright AA, Katz IT. Beyond burnout-Redesigning care to restore meaning and sanity for physicians. N Engl J Med. 2018; 378(4):309-311

2. Maslach C, Schaufeli WB, Leiter MP. Job burnout. Annu Rev Psychol. 2001;52:397-422.

3. van der Heijden F, Dillingh G, Bakker A, Prins J. Suicidal thoughts among medical residents with burnout. Arch Suicide Res. 2008;12(4):344-346.
4. Wurm W, Vogel K, Holl A, Ebner C, Bayer D, et al. Depression-burnout overlap in physicians. PLoS One. 2016;11(3):e0149913.

5. Panagioti M, Panagopoulou E, Bower P, Lewith G, Kontopantelis E, Chew-Graham C, et al. Controlled interventions to reduce burnout in physicians: a systematic review and meta-analysis. JAMA Intern Med. 2017;177(2):195-205. https://doi.org/10.1001/jamainternmed.2016. 7674 .

6. Linzer M, Manwell LB, Williams ES, Bobula JA, Brown RL, Varkey AB, et al. MEMO (Minimizing Error, Maximizing Outcomes) Investigators. Working conditions in primary care: physician reactions and care quality. Ann Intern Med. 2009;151(1):28-36, W6-9.

7. Haas JS, Cook EF, Puopolo AL, Burstin HR, Cleary PD, Brennan TA. Is the professional satisfaction of general internists associated with patient satisfaction? J Gen Intern Med. 2000;15(2):122-8.

8. Kushnir T, Greenberg D, Madjar N, Hadari I, Yermiahu Y, Bachner YG. Is burnout associated with referral rates among primary care physicians in community clinics? Fam Pract. 2014;31(1):44-50. https://doi.org/10. 1093/fampra/cmt060.

9. Salyers MP, Bonfils KA, Luther L, Firmin RL, White DA, Adams EL, Rollins AL. The relationship between professional burnout and quality and safety in healthcare: a meta-analysis. J Gen Intern Med. 2017;32(4):475-482.

10. Shanafelt TD, Bradley KA, Wipf JE, Back AL. Burnout and selfreported patient care in an internal medicine residency program. Ann Intern Med. 2002;136(5):358-67.

11. Shanafelt TD, Mungo M, Schmitgen J, Storz KA, Reeves D, Hayes SN, et al. Longitudinal study evaluating the association between physician burnout and changes in professional work effort. Mayo Clin Proc. 2016;91(4):422-431

12. Sinsky CA, Dyrbye LN, West CP, Satele D, Tutty M, Shanafelt TD. Professional satisfaction and the career plans of US physicians. Mayo Clin Proc. 2017;92(11):1625-1635.

13. Rabatin J, Williams E, Manwell LB, Schwartz MD, Brown RL, Linzer M. Predictors and outcomes of burnout in primary care physicians. J Prim Care Community Health. 2016;7(1):41-43. https://doi.org/10. 1177/2150131915607799.

14. Edwards ST, Marino M, Balasubramanian BA, Valenzuela S, Springer $\mathbf{R}$, Preston A, Solberg $\mathbf{L}$, et al. Burnout among providers and staff in small to medium size primary care practices: early findings from EvidenceNOW. Presentation slides at Society of General Internal Medicine National Meeting, April 20, 2017.

15. Puffer JC, Knight C, O'Neill TR, Rassolian M, Bazemore AW, Peterson LE, Baxley EG. Prevalence of burnout in board certified family physicians. J Am Board Fam Med, 2017;30:125-126.

16. Helfrich C, Dolan E, Simonetti J, Reid RJ, Joos S, Wakefield BJ, et al. Elements of team-based care in a patient-centered medical home are associated with lower burnout among VA primary care employees. J Gen Intern Med, 2014;29(2):s659-666.

17. Nutting PA, Crabtree BF, Miller WL, Stewart EE, Stange KC, Jaén CR. Journey to the patient-centered medical home: a qualitative analysis of the experiences of practices in the National Demonstration Project. Ann Fam Med. 2010;8:(1)s45-56. https://doi.org/10.1370/afm. 1075.

18. Reid RJ, Coleman K, Johnson EA, Fishman PA, Hsu C, Soman MP, et al. The group health medical home at year two: cost savings, higher patient satisfaction, and less burnout for providers. Health Aff (Millwood). 2010;29(5):835-43.

19. Reid RJ, Fishman PA, Onchee Y, Ross TR, Tufano JT, Soman MP, et al. Patient-centered medical home demonstration: a prospective, quasi-experimental, before and after evaluation. Am J Man Care. 2009; 15(9):e7 1-87.

20. Simonetti, JA, Nelson K, Mohrn D, Schectman G, Helfrich C. Patientcentered medical home implementation and burnout among VA primary care employees. J Ambul Care Manage. 2017;40(2):158-166.

21. Friedberg MW, Reid RO, Timbie JW, Setodji C, Kofner A, Weidmer B, et al. Federally qualified health center clinicians and staff increasingly dissatisfied with workplace conditions. Health Aff. 2017;36(8):1469-75.

22. Peikes D, Anglin G, Taylor E, Dale S, O'Malley A, Ghosh A, et al. Evaluation of the Comprehensive Primary Care initiative: Third annual report. Prepared for the Centers for Medicare \& Medicaid Services. Princeton, NJ: Mathematica Policy Research, December 2016. Available at https://innovation.cms.gov/Files/reports/cpci-evalrpt3.pdf.

23. Dale SB, Ghosh A, Peikes DN, Day TJ, Yoon FB, Taylor EF, et al. Two-year costs and quality in the Comprehensive Primary Care initiative. N Engl J Med. 2016;374:2345-56. https://doi.org/10.1056/NEJMsa1414953.

24. Maslach CJS, Leiter MP. Maslach burnout inventory manual. 3. Palo Alto: Consulting Psychologists Press; 1996. 
25. Federally Qualified Health Center Advanced Primary Care (FQHC APCP) Demonstration Clinician and Staff Experience Survey (Draft). Described in Kahn KL, Timbie JW, Friedberg MW, Lavelle TA, Mendel P, Ashwood JS, et al. Evaluation of CMS FQHC APCP demonstration: second annual report. July 2015. RR-886/1-CMS. Prepared for the Centers for Medicare \& Medicaid Services. Santa Monica, CA: RAND Corporation. Available at: https://innovation.cms.gov/Files/reports/fqhc-scndevalrpt.pdf. Accessed 12 November 2017.

26. West C, Dyrbye L, Sloan J, Shanafelt T. Single item measures of emotional exhaustion and depersonalization are useful for assessing burnout in medical professionals. J Gen Intern Med. 2009;24(12):1318-21.

27. Schmoldt RA, Freeborn DK, Klevit HD. Physician burnout: recommendations for HMO managers. HMO Pract. 1994;8:58-63.

28. McManus IC, Winder BC, Gordon D. The causal links between stress and burnout in a longitudinal study of UK doctors. Lancet. 2002;359:2089-90. https://doi.org/10.1016/S0140-6736(02)08915-8

29. Linzer M, Manwell LB, Mundt M, Williams E, Maguire A, McMurray J, et al. Organizational climate, stress, and error in primary care: the MEMO study findings. In: Henriksen K, Battles JB, Marks ES, Lewin DI, eds. Advances in patient safety: from research to implementation volume 1: research findings. Rockville: Agency for Healthcare Research and Quality; 2005:65-77.

30. Linzer M, Sinsky CA, Poplau S, Brown R, Williams E, and the Healthy Workplace Investigators. Joy in medical practice: clinician satisfaction in the healthy work place trial. Health Aff. 2017;36(10):1808-14.

31. West CP, Dyrbye LN, Erwin PJ, Shanafelt TD. Interventions to prevent and reduce physician burnout: a systematic review and meta-analysis. Lancet. 2016. https://doi.org/10.1016/S0140-6736(16)31279-X.

32. Linzer M, Poplau S, Grossman E, Varkey A, Yale S, Williams E, et al. A cluster randomized trial of interventions to improve work conditions and clinician burnout in primary care: results from the Healthy Work Place (HWP) study. J Gen Int Med. 2015;30(8):1105-11. https://doi.org/10. 1007/s11606-015-3235-4

33. The American Association for Public Opinion Research. 2016. Standard definitions. Final dispositions of case codes and outcome rates for surveys, revised 2016. Available at: http://www.aapor.org/AAPOR Main/media/publications/Standard-Definitions20169theditionfinal.pdf. Accessed 1 November 2017. 